\title{
Determination of Plutonium and Uranium Radionuclides in Glacier Ice Samples by MC-ICP-MS
}

\author{
Stefan Röllina ${ }^{\mathrm{a}}$, Hans Sahlia, Lars Gnägibc ${ }^{\mathrm{b}}$, and José A. Corcho Alvarado*a
}

\begin{abstract}
A radiochemical procedure for the determination of plutonium $(\mathrm{Pu})$ and uranium $(\mathrm{U})$ radionuclides in ice samples by multicollector inductively coupled plasma mass spectrometer (MC-ICP-MS) is presented. Pu and $U$ radionuclides are preconcentrated by coprecipitation and then separated by extraction chromatography. The purified Pu and $\mathrm{U}$ fractions are analyzed by MC-ICP-MS. Detection limits of $2 \times 10^{-3}$ and $3 \times 10^{-6} \mathrm{mBq} \mathrm{kg}^{-1}$ were achieved for ${ }^{239} \mathrm{Pu}$ and ${ }^{236} \mathrm{U}$, respectively. Surface ice samples collected from the Gauli glacier (Switzerland) were analyzed by this method. The surface of the Gauli Glacier retains historical records of ${ }^{239} \mathrm{Pu}$, ${ }^{240} \mathrm{Pu}$ and ${ }^{236} \mathrm{U}$ from the nuclear weapon testing (NWT) period. Pu and $U$ radionuclides were found to be consistent in terms of pattern, showing two peaks possibly related to the two main periods of the NWTs (1954-1958 and 1961-1963). ${ }^{3} \mathrm{H}$ measurements, also released by the NWT, further confirmed the $\mathrm{Pu}$ and $\mathrm{U}$ results. The ${ }^{240} \mathrm{Pu} /{ }^{239} \mathrm{Pu}$ ratio ranged from 0.14 to 0.25 , and ${ }^{236} \mathrm{U} /{ }^{239} \mathrm{Pu}$ ranged from 0.14 to 0.81 . The $\mathrm{Pu}$ atom ratios ranged within the limits of global fallout in the most intensive period of NWT (1952 to 1962).
\end{abstract}

Keywords: Gauli glacier $\cdot \mathrm{MC}-\mathrm{ICP}-\mathrm{MS} \cdot{ }^{239} \mathrm{Pu} \cdot{ }^{240} \mathrm{Pu} /{ }^{239} \mathrm{Pu} \cdot{ }^{236} \mathrm{U}$

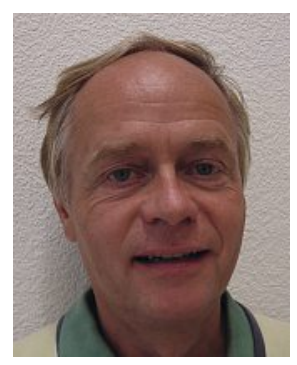

Stefan Röllin studied analytical chemistry at the Swiss Federal Institute of Technology in Zürich (1986-1991). From 1992-1996 he carried out his $\mathrm{PhD}$ in the Hot Laboratory of the Paul Scherrer Institute. From 19972001 he worked in the Hot Cell Laboratory at Studsvik Nuclear AB (Sweden). Since 2001 Stefan is working at the Nuclear Chemistry Division of Spiez Laboratory as Research Scientist.

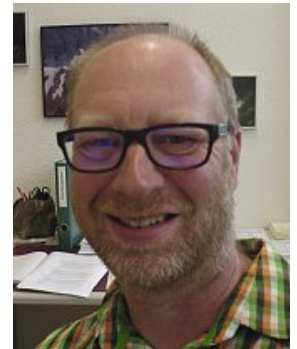

Hans Sahli made an apprenticeship as chemical laboratory assistant at the armasuisse in Thun (1988-1991). From 1991 to 1999 he worked in the testing group for plastics and polymers, first in Thun and later at Spiez laboratory. In 1999, he moved inhouse to the group of environmental analytics and radiochemistry. From 2003 to 2006, Hans made a further education as scientific laboratory technician and is nowadays head of the Radiochemistry Testing Group.

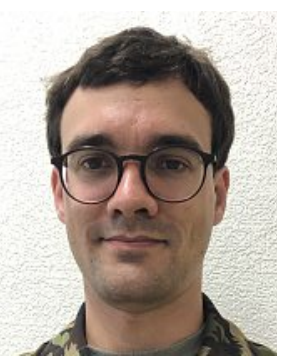

Lars Gnägi serves as first lieutenant of the Swiss Armed Forces NBC defense laboratory 1 where he is the platoon leader of the radiochemistry branch. He organized the logistics, led the sample collection and coordinated the laboratory work of this project. Lars studied chemistry at the University of Bern and is currently pursuing a $\mathrm{PhD}$ in chemistry at the same institution.

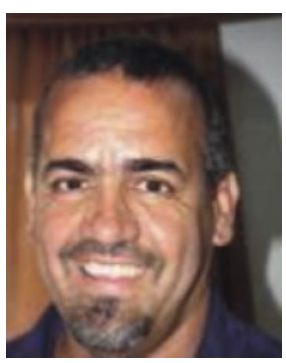

José A. Corcho Alvarado studied Radiochemistry at the Institute of Nuclear Sciences and Technology in Havanna (1989_ 1994, Cuba). From 1995 to 2000, he worked as radiochemist at the Center for Radiation Protection and Hygiene in Havanna (Cuba). In 2000, he joined the group of Prof. P.G. Appleby (Environmental Radioactivity Research Center, University of Liverpool, UK) as research assistant. In 2001, José moved to the Climate and Environmental Physics Division of the Physics Institute, University of Bern, where he completed his $\mathrm{PhD}$ in 2005 under the supervision of Dr. R. Purstchert and Prof. T. Stocker. In 2006, he joined the Earth Science Department of the Paris-Sud University (Orsay, France) as postdoc. From 2008 till 2012, he worked at the Radioecology Group of the Institute of Radiation Physics in Lausanne (CHUV). Since October 2012, José is working at the Nuclear Chemistry Division of Spiez Laboratory as Research Scientist.

\section{Introduction}

Alpine glaciers are an important source of historical information on past atmospheric pollution and climate change. The age range of the alpine glaciers vary typically between 100 and 1000 years. ${ }^{[1]}$ Obtaining an accurate and reliable ice core chronology, needed to interpret any proxy time series, is often a challenge. ${ }^{[2]}$ Radiometric methods based on the analysis of artificial fallout radionuclides are widely used for this purpose.[2,3]

Aboveground nuclear weapons testing during the 1950s and 1960 s is the major source of artificial radionuclides in the global environment. ${ }^{[4]}$ During the testing period, large amounts of these radionuclides were injected into the stratosphere, which then 
slowly returned into the troposphere. ${ }^{[5]}$ A significant injection of artificial radionuclides into the stratosphere started in 1952 and reached a maximum in the Northern Hemisphere in 1962. ${ }^{[4]}$ These well-dated nuclear fallout features are found in ice layers and widely used to develop ice core chronologies. ${ }^{[2,3,6]}$

Among the artificial radionuclides, plutonium-239 $\left({ }^{239} \mathrm{Pu}\right.$, halflife: $24100 \mathrm{yr})$, plutonium-240 $\left({ }^{240} \mathrm{Pu}\right.$, half-life: $\left.6561 \mathrm{yr}\right)$, and tritium $\left({ }^{3} \mathrm{H}\right.$, half-life: $\left.12.31 \mathrm{yr}\right)$ have found important use in dating ice cores with ages up to $70 \mathrm{yr}$ old. ${ }^{[2,3,6 \mathrm{~b}]}$ Other radionuclides such as uranium-236 ( ${ }^{236} \mathrm{U}$, half-life: $2.310^{7} \mathrm{yr}$ ) are less reported, mainly due to the high analytical demands to detect them. ${ }^{[7]} \mathrm{Pu}$ and $\mathrm{U}$ radionuclides are nowadays routinely measured by mass spectrometry techniques. ${ }^{[2,3]}$ Through this analysis, information on the isotope ratios $\left(\right.$ e.g. $\left.{ }^{240} \mathrm{Pu} /{ }^{239} \mathrm{Pu}\right)$ is obtained. ${ }^{[8]}$ This information is particularly important for assessing different sources of plutonium contamination. ${ }^{[9]}$

$\mathrm{Pu}$ and $\mathrm{U}$ radionuclides need to be purified from the matrix and potential interferences by refined radiochemical methods in order to measure them accurately. ${ }^{[6 a, 7]}$ Activity concentrations of $\mathrm{Pu}$ radionuclides in ice samples are very low in the order of few to several hundred $\mu \mathrm{Bq}$ per $\mathrm{kg}$ ice. ${ }^{[6 a, b, 10]}$ The corresponding low number of atoms $\left(1 \mu \mathrm{Bq}\right.$ of ${ }^{239} \mathrm{Pu}$ corresponds to $1.09710^{6}$ atoms of ${ }^{239} \mathrm{Pu}$, and $0.43510^{-15} \mathrm{~g}$ of ${ }^{239} \mathrm{Pu}$ ) necessitates samples of several $\mathrm{kg}$ ice. ${ }^{[7]}$ This large sample size hinders routine measurements of ice samples. Here we show that our radiochemical method for analyzing $\mathrm{Pu}$ isotopes reduces the required sample of ice to maximum 1 kg (Fig. 1).

We present a radiochemical procedure for the determination of $\mathrm{Pu}$ and $\mathrm{U}$ radionuclides in ice samples by MC-ICP-MS. The procedure is based on the use of extraction chromatography resins in combination with co-precipitation methods. The amount of ${ }^{242} \mathrm{Pu}$ used as radiochemical yield tracer has been optimized in order to reduce the potential contamination of the analyte of interest by impurities present in the tracer. In a second part of this work, the radiochemical method is applied to determine these artificial radionuclides in surface ice samples collected at the Gauli Glacier (Switzerland, Fig. 1). We analyzed the quantity of Pu and $\mathrm{U}$ radionuclides and the atom ratios ${ }^{240} \mathrm{Pu} /{ }^{239} \mathrm{Pu}$ and ${ }^{236} \mathrm{U} /{ }^{239} \mathrm{Pu}$ in glacial ice. We aimed at investigating the absolute age of glacier surface ice. ${ }^{[6 c]}$ For cross checking the $\mathrm{Pu}$ and $\mathrm{U}$ data, measurements of tritium $\left({ }^{3} \mathrm{H}\right)$ in aliquots of the same samples were performed.

\section{Experimental}

\subsection{Reagents and Equipment}

All reagents were of analytical grade. Deionized water from an arium $^{\circledR}$ pro UF Ultrapure Water system (Sartorius), 65\% nitric acid p.a. (prepared on a quartz sub-boiling apparatus), $40 \%$ hydrofluoric acid suprapur, $37 \%$ hydrochloric acid suprapur and ammonium iron (II) sulphate hexahydrate pro analysis (all from Merck) were used for the analyses. Uranium isotope standard IRMM-187 and IRMM-184 (all from Joint Research Centre, Belgium) were used for isotope ratio calibration and validation. A standard solution of ${ }^{242} \mathrm{Pu}$ (Joint Research Centre, Belgium) was used as radiochemical yield tracer. Standard solutions of uranium, thorium (Th) and indium (In) were purchased from Alfa Aesar (Germany). The extraction chromatography resins TEVA and UTEVA were purchased from Triskem International (Bruz, France). The certified reference material IAEA-381 (Irish Sea Water) was obtained from the International Atomic Energy Agency (Vienna, Austria). All $\mathrm{U}$ and $\mathrm{Pu}$ radionuclide measurements were performed on a MC-ICP-MS Neptune (Thermo-Fisher). The U content in the melted ice samples was analyzed in a sector field sf-ICP-MS Element 2 (Finnigan MAT, Germany). The ${ }^{3} \mathrm{H}$ measurements were performed in an ultra-low level liquid scintillation counter (LSC) Quantulus 1220 (PerkinElmer).

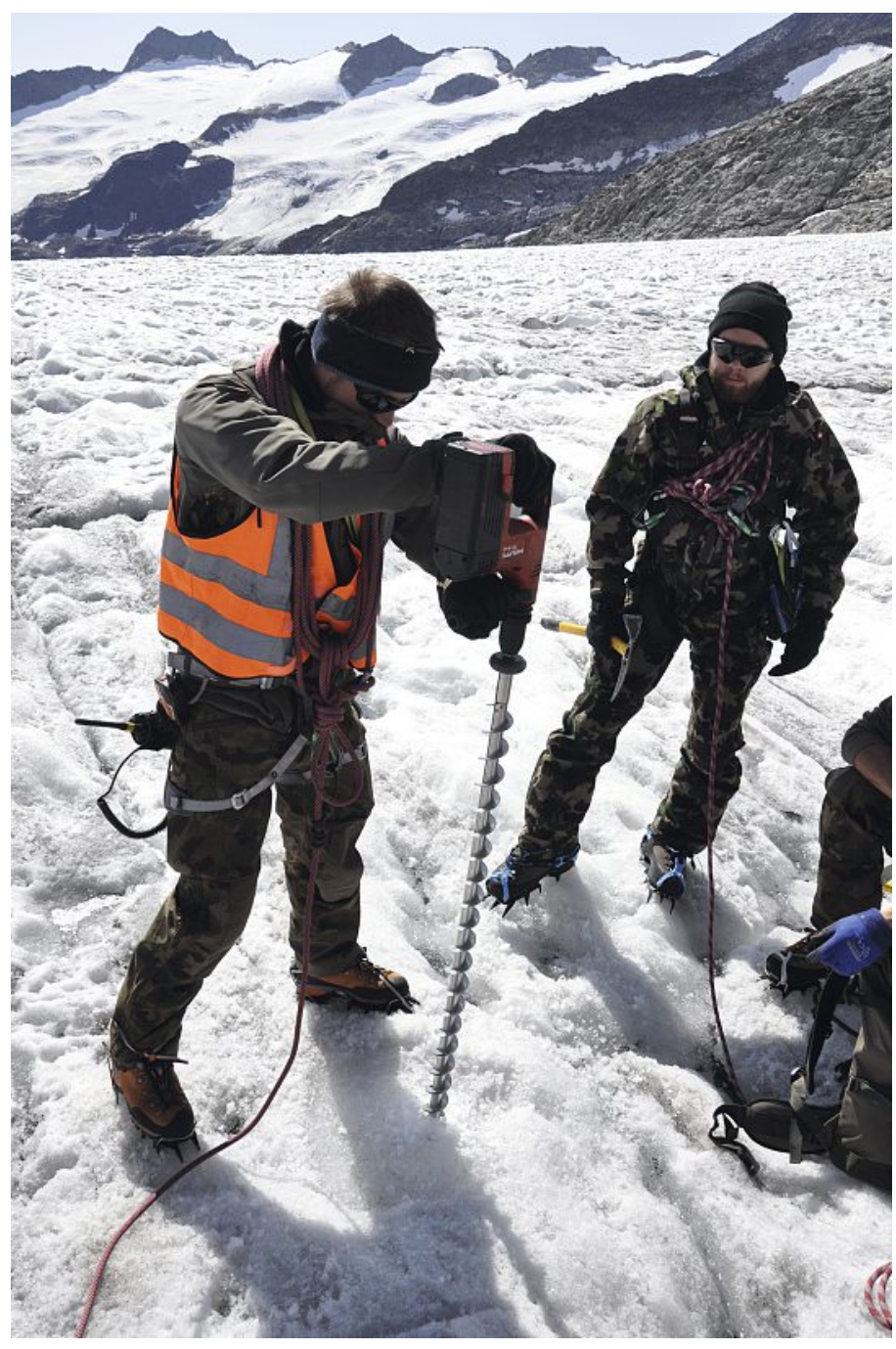

Fig. 1. Sampling ice at the Gauli Glacier (Photo courtesy of L. Gnägi).

\subsection{Glacial Ice Sampling and Sample Preparation}

More than two hundred glacier surface ice samples were collected in summer 2019 from the Gauli Glacier. Detailed information on the sampling work is published elsewhere. ${ }^{[6 c]}$ Briefly, the ice samples were collected by the 2nd company of the Swiss Armed Forces' NBC Defence Laboratory 1 during the Refresher Course (Wiederholungskurse, WK), with the support of the Swiss Armed Forces Alpine Command and the Swiss Air Force (Fig. 1). The surface ice was sampled at intervals of 25 to $50 \mathrm{~m}$ in lines roughly following the glacier flowlines, and from a region identified by flow models to most likely contain ice from the period 1950 s to 1970 s. ${ }^{[6 c]}$ The amount of water recovered from each ice sample was about $1.2 \mathrm{~kg}$. During three weeks, the radiochemistry group of the $2 \mathrm{nd}$ company of the Swiss Armed Forces' NBC Defence Laboratory 1 processed over 200 samples for $\mathrm{Pu}$ and $\mathrm{U}$ analysis as described below. Here we report results of only one of the sampled lines.

All ice melt samples were acidified with conc. $\mathrm{HNO}_{3}$ (about 6 $\mathrm{mL}$ per $\mathrm{kg}$ water). An aliquot of $50 \mathrm{~mL}$ of each sample was used for tritium analyses. All aliquots for tritium were distilled as explained elsewhere, ${ }^{[11]}$ and the distillate counted by LSC. A detection limit for ${ }^{3} \mathrm{H}$ of $9.8 \mathrm{TU}$ ( $1 \mathrm{TU}$ equal to $0.118 \mathrm{~Bq} \mathrm{~kg}^{-1}$ ) was achieved for a counting time of $1440 \mathrm{~min}$. About $20 \mathrm{~mL}$ of each sample was taken to analyze the U content in a sf-ICP-MS Element 2. This information is used to calculate the $\mathrm{U}$ separation yield and to quantify ${ }^{236} \mathrm{U}$ in the final $U$ fractions. The remainder of the water sample was spiked with about $0.3 \mathrm{pg}$ of ${ }^{242} \mathrm{Pu}$ as radiochemical yield tracer. The certified reference material IAEA-381 and blank samples (deionized water) were also analyzed in the same way. 
The $\mathrm{Pu}$ and $\mathrm{U}$ radionuclides were separated and purified using extraction chromatography materials (TEVA and UTEVA resins), following methods described elsewhere. ${ }^{[8,12]}$ Briefly, Pu and U radionuclides were concentrated by co-precipitation with $\mathrm{Fe}(\mathrm{OH})_{3}$ at $\mathrm{pH}$ 6. The precipitate was dissolved in a few $\mathrm{mL}$ of $\mathrm{HNO}_{3} 4.5$ $\mathrm{M}$, and a few $\mathrm{mg}$ of ammonium iron (II) sulphate hexahydrate were added to the solution to adjust the oxidation state of $\mathrm{Pu}$ to $(4+) .{ }^{[12]} \mathrm{Pu}$ was then separated from $\mathrm{U}$ and Th (thorium) using a $2 \mathrm{~mL}$ TEVA column. This resin is selective to elements with (4+) valence state. After conditioning the TEVA resin, the sample was loaded and the breakthrough containing the $\mathrm{U}(6+)$ radioisotopes was collected for further purification. The TEVA column was rinsed with $25 \mathrm{~mL}$ of $\mathrm{HCl} 6 \mathrm{M}$ (to remove Th radioisotopes) and then with $50 \mathrm{~mL}$ of a $3 \mathrm{M} \mathrm{HNO}_{3}$ solution. $\mathrm{Pu}$ radionuclides were eluted in $20 \mathrm{~mL}$ as described elsewhere. ${ }^{[13]} \mathrm{A}$ known amount of an In standard solution was added to the $\mathrm{Pu}$ fraction for the MCICP-MS measurement.

The UTEVA resin was used to separate and purify the U radioisotopes. ${ }^{[13]}$ After conditioning the TEVA resin, the sample (breakthrough from the TEVA resin) was loaded onto the UTEVA resin. The column was rinsed with $10 \mathrm{~mL} \mathrm{HCl} 6 \mathrm{M}$ and then with $10 \mathrm{~mL}$ $\mathrm{HNO}_{3} 3 \mathrm{M}$. U radioisotopes were eluted with $20 \mathrm{~mL}$ of a $0.2 \%$ $\mathrm{HNO}_{3} / 0.002 \% \mathrm{HF}$ solution. A known amount of an In standard solution was added to the $\mathrm{U}$ fraction for the MC-ICP-MS measurement.

\subsection{Radionuclide Measurement}

The mass spectrometry (MS) analysis of $\mathrm{Pu}$ and $\mathrm{U}$ radionuclides was carried out using a MC-ICP-MS Neptune equipped with nine Faraday collectors and five ion counters (SEM). Aqueous solutions were introduced in the MC-ICP-MS using a CETAC Arridus II desolvator (Elemental Scientific Inc.) to enhance the signal and to achieve low hydride and oxide formation. All $\mathrm{Pu}$ isotopes were measured with the SEM detectors. In this configuration, the sensitivity for actinide isotopes in the eluate was about 150 counts per second (cps) per one $\mathrm{fg} \mathrm{mL}^{-1}$ which led to a signal for the ${ }^{242} \mathrm{Pu}$ tracer in the Pu-eluates $\left(15 \mathrm{fg} \mathrm{mL}^{-1}{ }^{242} \mathrm{Pu}\right)$ of $2000 \mathrm{cps}$. $\mathrm{Pu}$ isotope concentrations were calculated from the signal of the ${ }^{242} \mathrm{Pu}$ tracer. The contributions of the $\mathrm{Pu}$ isotopes from the tracer and tailing from $U$ and $T h$ were corrected mathematically based on the isotope ratios from the certificate and abundance sensitivity measurements of $\mathrm{U}$ and $\mathrm{Th}$ standards. The total acquisition time per sample was $3 \mathrm{~min}$. The ${ }^{239} \mathrm{Pu}$ signal was $3000 \mathrm{cps}$ for the samples with the highest $\mathrm{Pu}$ concentrations. The detection limit was around 1000 times lower, which corresponds to concentrations of $900 \mathrm{ag}(\operatorname{attogram}){ }^{239} \mathrm{Pu}$ in one $\mathrm{kg}$ of ice $\left(1 \mathrm{ag}=10^{-18} \mathrm{~g}\right)$.

${ }^{235} \mathrm{U}$ and ${ }^{238} \mathrm{U}$ were measured by Faraday detectors and the minor uranium isotopes by SEM detectors. The uranium tailing for the minor isotopes was corrected with a baseline subtraction. For the measurement of ${ }^{236} \mathrm{U}$, a RPQ filter was used to lower the abundance sensitivity. Tailing contribution in the order of $10^{-8}$ was corrected. The total acquisition time per sample was 18 min. Standard sample bracketing using the IRMM-187 uranium isotope standard was applied for all measurements. IRMM-184 uranium isotope standard solutions with approximately the same uranium concentrations as in the uranium eluates were used for quality assurance.

\section{Results}

The results of the analysis of the certified reference material IAEA-381 are given in Table 1 . The $\mathrm{Pu}$ radiochemical yield in both measurements was nearly $100 \%$. Measured ${ }^{239} \mathrm{Pu}$ activity and ${ }^{240} \mathrm{Pu} /{ }^{239} \mathrm{Pu}$ atom ratio in the certified reference material were in good agreement with the target values. In all cases, the measured values are within the $95 \%$ confidence interval reported for this reference material. These results highlight the good precision and accuracy of the radiochemical method.

The analysis of ${ }^{239} \mathrm{Pu}$ in the blank samples was in all cases below the detection limit of $2 \mu \mathrm{Bq} \mathrm{kg}^{-1}$ [871 $\left.\mathrm{ag} \mathrm{kg}^{-1}\right]$. This detection limit is in the order of the ${ }^{239} \mathrm{Pu}$ concentrations ( 75 to $2823 \mathrm{ag} \mathrm{kg}^{-1}$ ) reported in freshly fallen snow in the Alps. ${ }^{[7]} \mathrm{A}$ few data exist for $\mathrm{Pu}$ in surface waters in Switzerland. For example, in surface water collected at Val Piora (Tessin), ${ }^{239+240} \mathrm{Pu}$ activity concentrations of 7 to $8 \mu \mathrm{Bq} \mathrm{kg}{ }^{-1}$ were reported. ${ }^{[14]}$ In spring water from the Chaudron Spring at the Venoge River, ${ }^{239+240} \mathrm{Pu}$ activity concentrations between 4 and $22 \mu \mathrm{Bq} \mathrm{kg}^{-1}$ were found.[15] Taking into account that $\mathrm{Pu}$ in these waters originated solely from NWTs, characterized by a ${ }^{240} \mathrm{Pu} /{ }^{239} \mathrm{Pu}$ activity ratio of 0.67 , activity concentrations of ${ }^{239} \mathrm{Pu}$ in surface water of 2.4 to $13.2 \mu \mathrm{Bq} \mathrm{kg}^{-1}$ can be calculated. Hence, our detection limit is below the ${ }^{239} \mathrm{Pu}$ activities reported in surface fresh water in Switzerland (2.4 to $\left.13.2 \mu \mathrm{Bq} \mathrm{kg}^{-1}\right)$. In all the above studies, sample volumes corresponding to 60 to $200 \mathrm{~kg}$ water were analyzed. Our method reduces the required water volume to about $1 \mathrm{~kg}$, while still achieving sufficiently low detection limits allowing to determine ${ }^{239} \mathrm{Pu}$ in most environmental waters and ice contaminated by the global fallout from the NWTs.

The ${ }^{236} \mathrm{U}$ concentration in global fallout from the NWTs follows the ${ }^{239} \mathrm{Pu}$ concentration and is assumed to be $1 / 3$ of the massic concentration of ${ }^{239} \mathrm{Pu}$. The detection limit for ${ }^{236} \mathrm{U}$ by ICP-MS depends on the natural $U$ concentration because of the tailing from the isotopes ${ }^{235} \mathrm{U}$ and ${ }^{238} \mathrm{U}$. The $\mathrm{U}$ concentration in glacier ice was in the range of $10^{-11}-10^{-10} \mathrm{~g}$ per $\mathrm{g}$ of ice. Because of the very low $\mathrm{U}$ concentrations, ${ }^{236} \mathrm{U} /{ }^{238} \mathrm{U}$ atom ratios of down to $10^{-5}$ were measured for glacier ice from the global fallout maximum. However, the natural $\mathrm{U}$ concentration in river waters is $10-100$ times higher and the ${ }^{239} \mathrm{Pu} 1000$ times lower than in ice samples. Therefore, ${ }^{236} \mathrm{U} /{ }^{238} \mathrm{U}$ atomic ratios are expected to be below $10^{-9}$. Such low atomic ratios can only be measured with thermal ionization mass spectrometry (TIMS) or accelerated mass spectrometry (AMS). ${ }^{[6]}$ The ${ }^{236} \mathrm{U}$ detection limit for ice samples was estimated to $0.003 \mu \mathrm{Bq} \mathrm{kg}{ }^{-1}$.

Radiochemical yields for $\mathrm{Pu}$ and $\mathrm{U}$ were above $90 \%$ in the majority of the ice samples, with typical values close to $100 \%$. Results of the ${ }^{239} \mathrm{Pu},{ }^{236} \mathrm{U}$ and ${ }^{3} \mathrm{H}$ activity concentrations and the ${ }^{240} \mathrm{Pu} /{ }^{239} \mathrm{Pu}$ and ${ }^{236} \mathrm{U} /{ }^{239} \mathrm{Pu}$ atom ratios in ice samples from one of the sampled flow lines of the Gauli Glacier are presented in Table 2. The profiles for ${ }^{3} \mathrm{H},{ }^{239} \mathrm{Pu}$ and ${ }^{236} \mathrm{U}$ activities are depicted in Fig. 2. All these radionuclides were found to be consistent in terms of pattern. The shapes of the ${ }^{3} \mathrm{H},{ }^{239} \mathrm{Pu}$ and ${ }^{236} \mathrm{U}$ profiles showed a clear maximum for the sample 246 . The ${ }^{239} \mathrm{Pu}$ and ${ }^{236} \mathrm{U}$ profiles depicted a second peak for the sample 248. The two peaks observed in the $\mathrm{Pu}$ and $\mathrm{U}$ profiles may be related to the two main periods of the atmospheric NWTs (1954-1958, 1961-1963). ${ }^{[4]}$ In the case of ${ }^{3} \mathrm{H}$, the second peak was not observed. Possibly, because of the

\begin{tabular}{|c|c|c|c|c|}
\hline & \multicolumn{2}{|c|}{ Measured values } & \multicolumn{2}{c|}{ Certified values } \\
\hline Sample & ${ }^{239} \mathbf{P u}$ & ${ }^{240} \mathbf{P u} /{ }^{239} \mathbf{P u}$ & ${ }^{239} \mathbf{P u}$ & ${ }^{240} \mathbf{P u} /{ }^{239} \mathbf{P u}$ \\
\hline & $\mathbf{m B q ~ k g}$ & atom ratio & $\mathbf{m B q ~ k g}^{-1}$ & atom ratio \\
\hline IAEA-381 & $0.0088 \pm 0.0003$ & $0.23 \pm 0.01$ & $0.0081 \pm 0.0010$ & $0.22 \pm 0.03$ \\
\hline IAEA-381 & $0.0085 \pm 0.0003$ & $0.23 \pm 0.01$ & $0.0081 \pm 0.0010$ & $0.22 \pm 0.03$ \\
\hline
\end{tabular}

Table 1. Results of ${ }^{239} \mathrm{Pu}$ activity and ${ }^{240} \mathrm{Pu} /{ }^{239} \mathrm{Pu}$ atom ratio in the certified reference material IAEA381. The expanded uncertainty $(\mathrm{k}=2)$ is reported. 


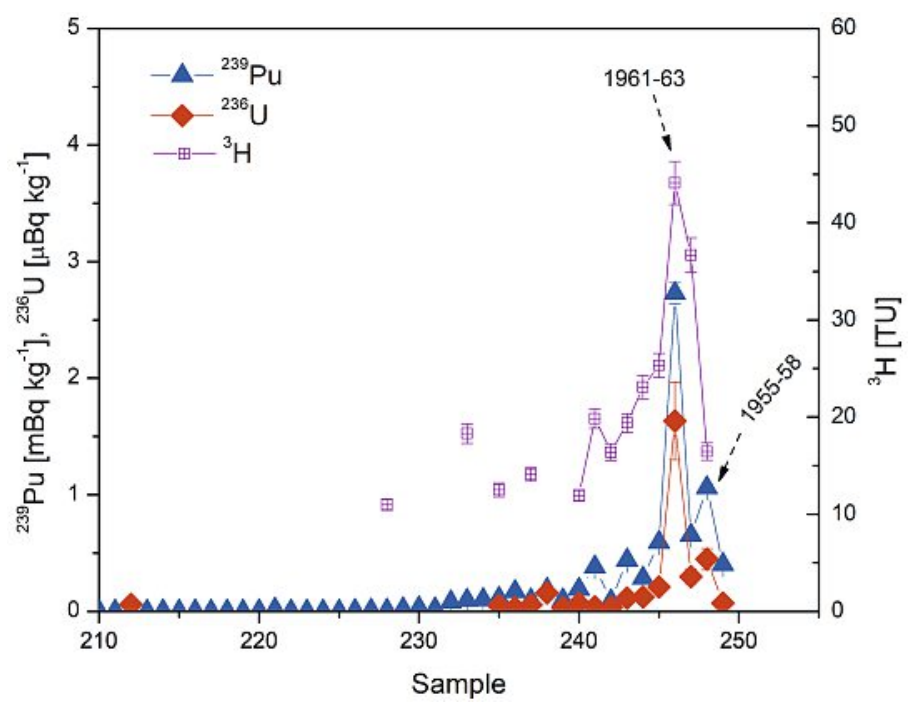

Fig. 2. Activities of ${ }^{239} \mathrm{Pu},{ }^{236} \mathrm{U}$ and ${ }^{3} \mathrm{H}$ along one sampled line from the Gauli Glacier (Switzerland). short half-life of this radionuclide, the originally deposited activity has nowadays decayed to levels below the detection limit of the method.

The highest activity of ${ }^{239} \mathrm{Pu}$ in surface ice from the Gauli Glacier was $2.7 \mathrm{mBq} \mathrm{kg}^{-1}$ (Table 2). This activity is about 2 to 3 times lower than the highest activities found in ice cores from Colle Gnifetti, in Switzerland $\left(7 \mathrm{mBq} \mathrm{kg}^{-1}\right)^{[10]}$ and the eastern Tien Shan, in Central Asia $(5.5 \mathrm{mBq} / \mathrm{kg})$. ${ }^{[6 \mathrm{a}]}$ However, it is slightly above the highest activity $(2.17 \mathrm{mBq} / \mathrm{kg})$ measured in an ice core extracted from the Dome du Gouter, Mont Blanc, France. ${ }^{[16]}$ The maximum activity of ${ }^{236} \mathrm{U}$ of $1.6 \mu \mathrm{Bq} \mathrm{kg}^{-1}$ (Table 2) is comparable to the maximum found in the ice core from the eastern Tien Shan glacier $(1.5 \mu \mathrm{Bq} / \mathrm{kg}) .{ }^{[6 a]}$ The ${ }^{3} \mathrm{H}$ profile showed a maximum activity of about $44 \mathrm{TU}$. Assuming that this ice corresponds to the year 1963 (maximum fallout from the NWTs), the ${ }^{3} \mathrm{H}$ activity at the snow deposition time would be $1020 \mathrm{TU}$. This calculated activity for 1963 is about 3 to 5 times lower than the ${ }^{3} \mathrm{H}$ activities reported in precipitation at mid-latitudes for this time period, ${ }^{[17]}$ which suggest that this ice does not correspond to the year 1963 . The ${ }^{3} \mathrm{H}$ and ${ }^{239} \mathrm{Pu}$ data indicate that the 1963 radioactive fallout maximum was most likely not found in the collected ice samples from the Gauli Glacier. Possibly, this peak was missed due to the 25 to 50 m sampling intervals (Fig. 3). [6c]

The ${ }^{240} \mathrm{Pu} /{ }^{239} \mathrm{Pu}$ atom ratios were found to range from $0.14( \pm$ $0.01)$ to $0.259( \pm 0.005)$, with an average value of $0.178( \pm 0.03)$. This average is similar to the ratio of $0.176( \pm 0.014)$ reported in global fallout from the NWTs. ${ }^{[18]}$ This result confirms that $\mathrm{Pu}$ contamination in the Gauli Glacier ice mainly originated from
Table 2. Results for the determination of ${ }^{239} \mathrm{Pu},{ }^{236} \mathrm{U}$ and ${ }^{3} \mathrm{H}$ activities, and ${ }^{240} \mathrm{Pu} /{ }^{239} \mathrm{Pu}$ and ${ }^{236} \mathrm{U} /{ }^{239} \mathrm{Pu}$ atom ratios, in ice samples collected from one line of the Gauli glacier (Switzerland). The expanded uncertainty $(\mathrm{k}=2)$ is reported. The reference date for decay correction is 27.08.2019.

\begin{tabular}{|c|c|c|c|c|c|}
\hline Sample & $\begin{array}{c}{ }^{239} \mathbf{P u} \\
{[\mu \mathbf{B q} \mathbf{k g}-1]}\end{array}$ & $\begin{array}{l}{ }^{240} \mathrm{Pu} /{ }^{239} \mathrm{Pu} \\
\text { atom ratio }\end{array}$ & $\begin{array}{c}{ }^{236} \mathbf{U} \\
{[\mu \mathbf{B q} \mathbf{k g}-1]}\end{array}$ & $\begin{array}{l}{ }^{236} \mathrm{U} /{ }^{239} \mathrm{Pu} \\
\text { atom ratio }\end{array}$ & $\begin{array}{c}{ }^{3} \mathrm{H} \\
{[\mathrm{TU}]}\end{array}$ \\
\hline 230 & $31 \pm 1$ & $0.14 \pm 0.01$ & $0.010 \pm 0.003$ & $0.30 \pm 0.09$ & $<9.8$ \\
\hline 231 & $21 \pm 1$ & $0.19 \pm 0.03$ & $0.016 \pm 0.005$ & $0.70 \pm 0.22$ & $<9.8$ \\
\hline 232 & $81 \pm 3$ & $0.21 \pm 0.01$ & $0.013 \pm 0.004$ & $0.15 \pm 0.05$ & $<9.8$ \\
\hline 233 & $97 \pm 3$ & $0.184 \pm 0.009$ & $0.04 \pm 0.01$ & $0.38 \pm 0.11$ & $18.3 \pm 1.0$ \\
\hline 234 & $101 \pm 4$ & $0.175 \pm 0.007$ & $0.017 \pm 0.005$ & $0.16 \pm 0.05$ & $<9.8$ \\
\hline 235 & $113 \pm 4$ & $0.169 \pm 0.009$ & $0.06 \pm 0.02$ & $0.51 \pm 0.15$ & $12.5 \pm 0.7$ \\
\hline 236 & $170 \pm 6$ & $0.259 \pm 0.005$ & $0.03 \pm 0.01$ & $0.19 \pm 0.06$ & $<9.8$ \\
\hline 237 & $98 \pm 4$ & $0.18 \pm 0.01$ & $0.07 \pm 0.02$ & $0.67 \pm 0.20$ & $14.1 \pm 0.7$ \\
\hline 238 & $187 \pm 7$ & - & $0.16 \pm 0.05$ & $0.81 \pm 0.25$ & $<9.8$ \\
\hline 239 & $99 \pm 4$ & $0.178 \pm 0.006$ & $0.04 \pm 0.01$ & $0.38 \pm 0.11$ & $<9.8$ \\
\hline 240 & $190 \pm 6$ & $0.209 \pm 0.007$ & $0.07 \pm 0.02$ & $0.36 \pm 0.11$ & $11.9 \pm 0.6$ \\
\hline 241 & $382 \pm 14$ & $0.152 \pm 0.006$ & $0.05 \pm 0.02$ & $0.14 \pm 0.04$ & $19.8 \pm 1.0$ \\
\hline 242 & $90 \pm 4$ & $0.177 \pm 0.005$ & $0.04 \pm 0.01$ & $0.44 \pm 0.13$ & $16.4 \pm 0.9$ \\
\hline 243 & $440 \pm 15$ & $0.169 \pm 0.005$ & $0.15 \pm 0.05$ & $0.32 \pm 0.10$ & $19.4 \pm 1.0$ \\
\hline 244 & $285 \pm 10$ & - & $0.13 \pm 0.04$ & $0.43 \pm 0.13$ & $23.1 \pm 1.2$ \\
\hline 245 & $592 \pm 21$ & $0.180 \pm 0.003$ & $0.26 \pm 0.08$ & $0.43 \pm 0.13$ & $25.3 \pm 1.2$ \\
\hline 246 & $2730 \pm 90$ & $0.179 \pm 0.003$ & $1.7 \pm 0.5$ & $0.59 \pm 0.18$ & $44.1 \pm 2.2$ \\
\hline 247 & $653 \pm 24$ & $0.184 \pm 0.004$ & $0.4 \pm 0.1$ & $0.55 \pm 0.17$ & $36.7 \pm 1.8$ \\
\hline 248 & $1060 \pm 36$ & $0.156 \pm 0.002$ & $0.5 \pm 0.1$ & $0.44 \pm 0.13$ & $16.5 \pm 0.9$ \\
\hline 249 & $404 \pm 14$ & $0.168 \pm 0.004$ & $0.10 \pm 0.03$ & $0.23 \pm 0.07$ & $<9.8$ \\
\hline
\end{tabular}




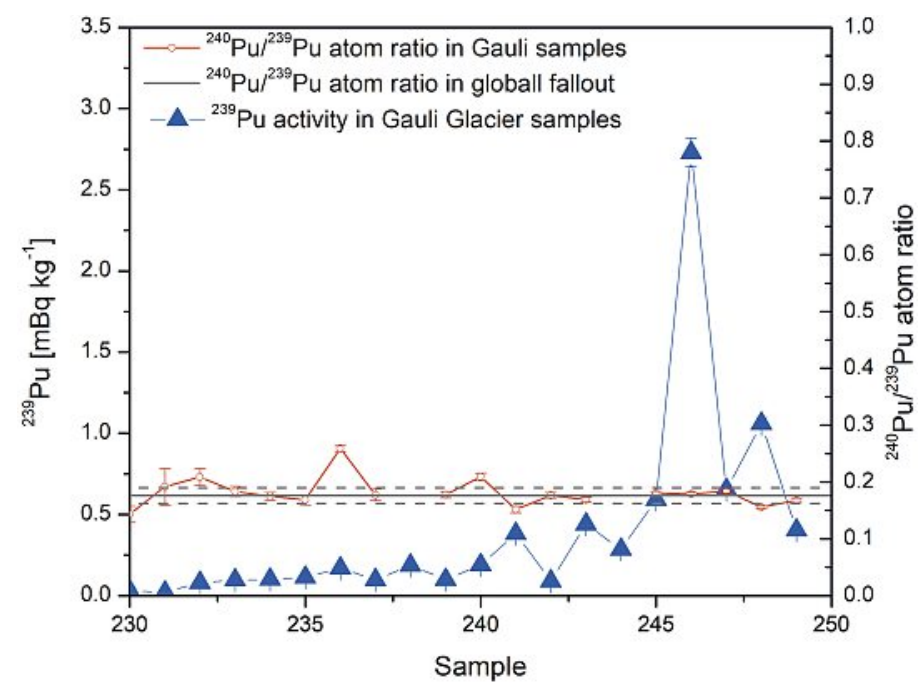

Fig. 3. Results for the determination of ${ }^{239} \mathrm{Pu}$ activities and ${ }^{240} \mathrm{Pu} /{ }^{239} \mathrm{Pu}$ atom ratios along one sampled line from the Gauli Glacier (Switzerland). The ${ }^{240} \mathrm{Pu} /{ }^{239} \mathrm{Pu}$ atom ratio typically found in global fallout is also represented $(0.176 \pm 0.014)$

this anthropogenic source. The ${ }^{236} \mathrm{U} /{ }^{239} \mathrm{Pu}$ atom ratios obtained in this work fall within a broad range from 0.14 to 0.81 , with an average value of $0.40( \pm 0.19)$. This range is similar to the ones reported in ice cores from the Austfonna Glacier in Svalbard $(0.18$ to 1.4$),{ }^{[19]}$ and from the eastern Tien Shan, in Central Asia (0.27 $\pm 0.09),{ }^{[6 a]}$ whereas for river water ${ }^{236} \mathrm{U} /{ }^{239} \mathrm{Pu}$ atom ratios up to 12 were found. ${ }^{[15]}$

Fig. 4 shows the determination of ${ }^{238} \mathrm{U}$ concentrations and ${ }^{235} \mathrm{U} /{ }^{238} \mathrm{U}$ atom ratios along one sampled line from the Gauli Glacier (Switzerland). The dashed line represents the range of the ${ }^{235} U /{ }^{238} U$ isotope ratio for natural uranium. ${ }^{[20]}$ Slightly enriched uranium was measured in the region of maximal global fallout similar to the ratios found for ice from the Dome du Gouter. ${ }^{[16]}$

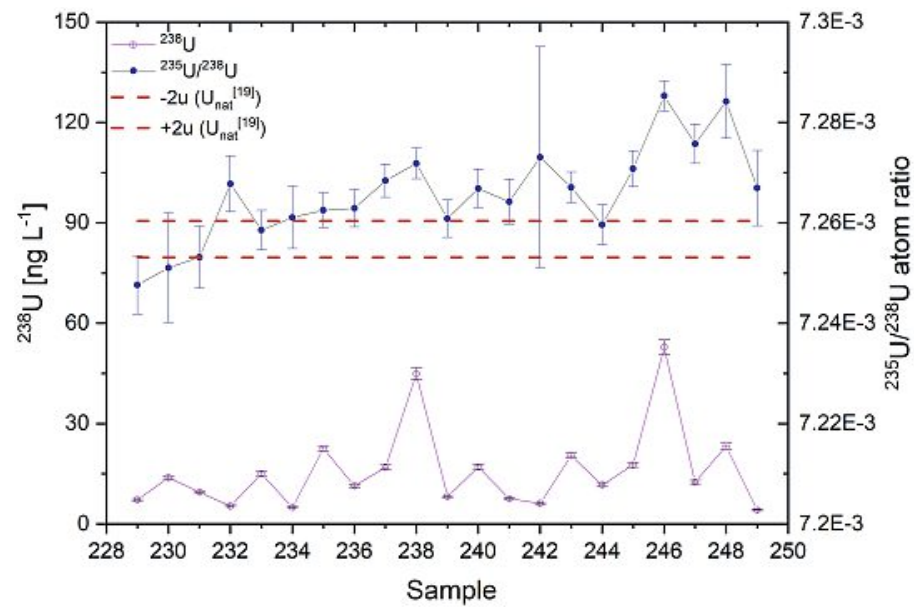

Fig. 4. Results for the determination of ${ }^{238} \mathrm{U}$ concentrations and ${ }^{235} \mathrm{U} /{ }^{238} \mathrm{U}$ atom ratios along one sampled line from the Gauli Glacier (Switzerland). The dashed line represents the range of the ${ }^{235} \mathrm{U} /{ }^{238} \mathrm{U}$ isotope ratio for natural uranium. ${ }^{[20]}$ Slightly enriched uranium was measured in the region of maximal global fallout (Samples 245 to 249).

\section{Conclusions}

The surface of the Gauli Glacier maintains historical records of ${ }^{3} \mathrm{H},{ }^{239} \mathrm{Pu},{ }^{240} \mathrm{Pu}$ and ${ }^{236} \mathrm{U}$ from the nuclear weapon testing (NWT) period. $\mathrm{Pu}$ and $\mathrm{U}$ radionuclides were found to be consistent in terms of pattern, showing two peaks possibly related to the two main periods of the NWTs (1954-1958 and 1961-1963). Measurements of ${ }^{3} \mathrm{H}$, also released by the NWTs, further confirmed the Pu and $\mathrm{U}$ results. The ${ }^{240} \mathrm{Pu} /{ }^{239} \mathrm{Pu}$ atom ratios confirmed that $\mathrm{Pu}$ contamination originated from the NWTs. Alpine glaciers maintain historical records of artificial fallout radionuclides from the atmospheric NWT period. This data is useful for knowing the absolute age of glacier surface ice. Data from mid-latitudinal alpine glaciers may be of special interest for better understanding interhemispheric transport of radionuclides released during the NWT events.

The optimization of the sample volume to about $1 \mathrm{~kg}$ ice facilitated the collection and transport of a large number of samples (more than 200 in this study) to the laboratory. This is usually not the case in other laboratories, where large sample volumes of more than $20 \mathrm{~kg}$ are required for the analysis. Moreover, the invaluable support of the Swiss Army in the radiochemistry laboratory allowed us to process and analyze all the samples in a short period of 3 weeks. A similar collaboration between Spiez Laboratory and the Swiss Army would take place in the event of any radiological or nuclear emergency in Switzerland.

\section{Acknowledgements}

The Swiss Armed Forces Alpine Command is acknowledged for its generous support of logistics and infrastructure during field work and sample collection. The authors thank the Swiss Air Force for multiple airlifts and material transport flights to the Gauli glacier. We thank the radiochemistry group from the 2nd company of the Swiss Armed Forces' NBC Defence Laboratory 1 (Michael Hofstetter, Marco Bernet, Chris Seitz, Etienne Trachsel, Yannick Suter, Joel Wasmer, and Michael Amacker) for extensive sample preparation, radiochemical workup, and sample analysis. Guillaume Jouvet (University of Zurich) is acknowledged for his support in the coordination of field work and for predictive modelling of the chosen site of sample collection.

Received: September 8, 2020

[1] Z. Feng, P. Bohleber, S. Ebser, L. Ringena, M. Schmidt, A. Kersting, P. Hopkins, H. Hoffmann, A. Fischer, W. Aeschbach, M. K. Oberthaler, Proc. Natl. Acad. Sci. USA 2019, 116, 8781, https://doi.org/10.1073/pnas.1816468116.

[2] H.Gäggeler, S.Sönke, 'NuclearDating', in 'ModernApplications', DeGruyter, Berlin, Boston, 2016, p. 133, https://doi.org/10.1515/9783110221862-006.

[3] P. Gabrielli, P. Vallelonga, in 'Environmental Contaminants: Using natural archives to track sources and long-term trends of pollution', Eds. J. M. Blais, M. R. Rosen, J. P. Smol, Springer Netherlands, Dordrecht, 2015, p. 393, https://doi.org/10.1007/978-94-017-9541-8_14.

[4] UNSCEAR, 'Sources and Effects of Ionizing Radiation', Vol. 1, UN, New York, 2000, p. 657.

[5] J. A. Corcho Alvarado, P. Steinmann, S. Estier, F. Bochud, M. Haldimann, P. Froidevaux, Nat. Commun. 2014, 5, 3030, https://doi.org/10.1038/ncomms4030.

[6] a) C. Wang, S. Hou, H. Pang, Y. Liu, H. W. Gäggeler, M. Christl, H.-A. Synal, J. Glaciology 2017, 63, 929, https://doi.org/10.1017/jog.2017.59; b) S. Olivier, S. Bajo, L. K. Fifield, H. W. Gäggeler, T. Papina, P. H. Santschi, U. Schotterer, M. Schwikowski, L. Wacker, Environ. Sci. Technol. 2004, 38 , 6507, https://doi.org/10.1021/es0492900; c) G. Jouvet, S. Röllin, H. Sahli, J. Corcho, L. Gnägi, L. Compagno, D. Sidler, M. Schwikowski, A. Bauder, M. Funk, The Cryosphere Discuss. 2020, https://doi.org/10.5194/tc-2020-142.

[7] K. Gückel, T. Shinonaga, M. Christl, J. Tschiersch, Sci. Rep. 2017, 7, 11848, https://doi.org/10.1038/s41598-017-12079-y.

[8] S. Röllin, H. Sahli, R. Holzer, M. Astner, M. Burger, Appl. Radiat. Isot. 2009, 67, 821, https://doi.org/http://dx.doi.org/10.1016/j.apradiso.2009.01.041.

[9] R. Jakopic, S. Richter, H. Kühn, Y. Aregbe, J. Anal. Atom. Spectrom. 2010 25, 815, https://doi.org/10.1039/B925918J

[10] J. Gabrieli, G. Cozzi, P. Vallelonga, M. Schwikowski, M. Sigl, J. Eickenberg, L. Wacker, C. Boutron, H. Gäggeler, P. Cescon, C. Barbante, Atmos. Environ 2011, 45, 587, https://doi.org/http://dx.doi.org/10.1016/j.atmosenv.2010.10.039.

[11] P. E. Warwick, I. W. Croudace, A. G. Howard, Anal. Chim. Acta 1999, 382 , 225, DOI: http://dx.doi.org/10.1016/S0003-2670(98)00757-0.

[12] H. Sahli, S. Röllin, V. Putyrskaya, E. Klemt, B. Balsiger, M. Burger, J. A. Corcho Alvarado, J. Radioanal. Nucl. Chem. Art. 2017, 314, 2209, https://doi.org/10.1007/s10967-017-5621-3.

[13] H. Sahli, S. Röllin, J. A. Corcho Alvarado, J. Radioanal. Nucl. Chem. Art 2017, 311, 1633, https://doi.org/10.1007/s10967-016-5145-2.

[14] F. Luisier, J. A. Corcho Alvarado, P. Steinmann, M. Krachler, P. Froidevaux, J. Radioanal. Nucl. Chem. 2009, 281, 425,

https://doi.org/10.1007/s10967-009-0004-z. 
[15] P. Froidevaux, P. Steinmann, L. Pourcelot, Environ. Sci. Technol. 2010, 44, 8479, https://doi.org/10.1021/es100954h.

[16] T. Warneke, I. W. Croudace, P. E. Warwick, R. N. Taylor, Earth Planet Sci. Lett. 2002, 203, 1047,

https://doi.org/http://dx.doi.org/10.1016/S0012-821X(02)00930-5.

[17] IAEA/WHO, 'Global Network of Isotopes in Precipitation', 'The GNIP Database', 2020, accessible at: https://nucleus.iaea.org/wiser

[18] P. W. Krey, E. P. Hardy, C. Pachucki, F. Rourke, J. Coluzza, W. K. Benson, 'Mass isotopic composition of global fall-out plutonium in soil', IAEA, International Atomic Energy Agency (IAEA), 1976.

[19] C. C. Wendel, D. H. Oughton, O. C. Lind, L. Skipperud, L. K. Fifield, E. Isaksson, S. G. Tims, B. Salbu, Sci. Tot. Environ. 2013, 461-462, 734, https://doi.org/10.1016/j.scitotenv.2013.05.054.

[20] S. Richter, A. Alonso, W. D. Bolle, H. Kühn, A. Verbruggen, R. Wellum, P. D. P. Taylor, Int. J. Mass Spectrom. 2005, 247, 37 ,

https://doi.org/https://doi.org/10.1016/j.ijms.2005.07.008.
License and Terms

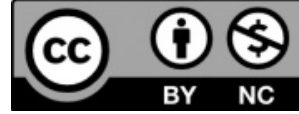

This is an Open Access article under the terms of the Creative Commons Attribution License CC BY_NC 4.0. The material may not be used for commercial purposes.

The license is subject to the CHIMIA terms and conditions: (http:// chimia.ch/component/sppagebuilder/?view=page $\& i d=12$ ).

The definitive version of this article is the electronic one that can be found at https://doi.org/10.2533/chimia.2020.989 